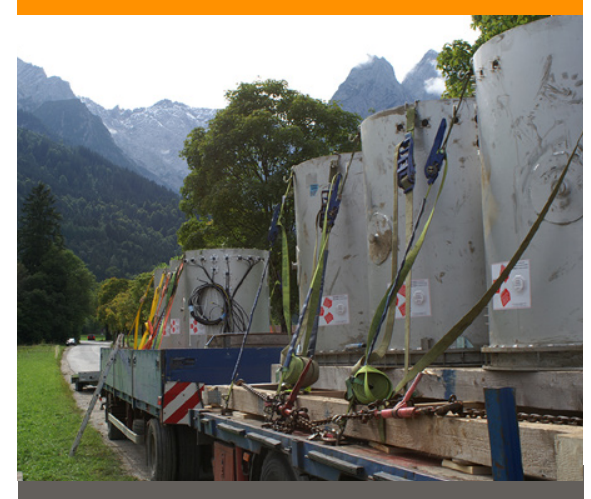

Core Ideas

- The water flux in lysimeters with a tension-controlled bottom boundary depends strongly on the applied pressure head.

- The surrounding subsurface conditions have a significant influence on the measured pressure heads that are used to control the bottom boundary of transferred lysimeters.

- Use of nonappropriate water table depths and soil textural properties which do not correspond to the conditions where the lysimeter originated can lead to large differences in soil water fluxes.

- The control of the bottom boundary of transferred lysimeters should be managed by measured pressure heads from the site where the lysimeter was taken from in order to enable a direct comparison of changes in soils and to investigate the effect of climate change on soil processes and soil functions.

J. Groh, J. Vanderborght, T. Pütz, and $\mathrm{H}$. Vereecken, Institute of Bio- and Geosciences: Agrosphere (IBG-3), Forschungszentrum Jülich $\mathrm{GmbH}, 52425$ Jülich, Germany. *Correspondingauthor (j.groh@fz-juelich.de).

Vadose Zone J.

doi:10.2136/vzj2015.08.0113

Received 19 Aug. 2015.

Accepted 2 May 2016.

Open access

Vol. 15, Iss. 7, 2016

(c) Soil Science Society of America.

This is an open access article distributed

under the CC BY-NC-ND license

(http://creativecommons.org/licenses/

by-nc-nd/4.0/).

\section{How to Control the Lysimeter Bottom Boundary to Investigate the Effect of Climate Change on Soil Processes?}

\author{
Jannis Groh,* Jan Vanderborght, Thomas Pütz, \\ and Harry Vereecken
}

A dynamic tension-controlled bottom boundary of lysimeters allows observing water and matter fluxes in lysimeters that are close to natural field conditions, as pressure heads at the lysimeter bottom are adjusted to measured pressure heads at the same depth in the surrounding field. However lysimeters are often transferred from their sampling location for practical reasons or to study, for example, the effect of climate change on soil functions. This transfer can be accompanied by a change aboveground but also in subsurface conditions that are used to control the bottom boundary and that may affect the soil water balance of lysimeters. This issue is also relevant for lysimeter stations which use a tension-controlled bottom boundary and are not directly installed near the site of excavation. The potential impact of different bottom boundary conditions on the water balance of lysimeters that were transferred in a climate impact experiment (SOILCan) was investigated exemplarily by a numerical study. Results showed that by using nonappropriate pressure heads, which were measured in soil profiles with a different texture and water table depth than the profile where the lysimeter was taken from, had partially large impacts on soil water fluxes, especially when the water table was located within a specific critical range. Different climate conditions between sampling and installation site were buffered by the soil and did not show a strong influence on the bottom boundary control of lysimeters when the groundwater table depth was assumed to remain constant. Considering a change in groundwater table depths due to changing climate tempered the effects of climate change on the soil water balance terms. In general, results demonstrate the importance of a proper control of the lysimeters bottom boundary conditions in studies that investigate the influence of climate change on soil functions and ecosystem variables by transferring lysimeter along climate gradients.

Abbreviations: BL, Bad Lauchstädt; Dd, Dedelow; $\mathrm{ET}_{\mathrm{a}^{\prime}}$ evapotranspiration; $\mathrm{ET}_{\mathrm{P}}$ potential evapotranspiration; LAl, leaf area index; Sb, Saverbach; Se, Selhausen.

Increasing variability of temperature and precipitation by climate change will affect the water availability, nutrient supply, and growth conditions for crop production (Thornton et al., 2014). Accurate and precise observations of the impact of climate variability and change on the water and matter fluxes in the unsaturated and saturated zone are therefore key information sources for the development of adaptation and management strategies of agricultural and environmental systems. Weighable lysimeters are frequently used tools to measure these fluxes in an entire soil profile (up to several meters deep) and provide us with observations that can be representative up to the field scale (Abdou and Flury 2004; Kasteel et al., 2007). Weighable lysimeters are vessels filled with disturbed or undisturbed soil volumes which are isolated from the surrounding field conditions. Lysimeters can be used to quantify the impacts of climate change on processes in the soil-vegetation-atmosphere continuum, for example, the influence of increasing soil temperature on dissolved organic carbon (Briones et al., 1998), of higher soil temperatures and $\mathrm{CO}_{2}$ - concentrations on the water and matter (carbon, nitrogen and phosphorus) budget 
of grassland (Herndl et al., 2011), of change in rainfall patterns on plant productivity for different soil types (Tataw et al., 2014), of decreasing rainfall and temperature on nitrate dynamics (Ineson et al., 1998), and the ecological controls on water-cycle response to climate variability in deserts (Scanlon et al., 2005).

In the context of growing interest in changes in the hydrological cycle due to climate change, an experimental lysimeter network (SOILCan [Zacharias et al., 2011]) was built up in Germany to study long-term effects of climate change on water and matter fluxes in soils and exchange of greenhouse gases. This network is embedded into the long-term observatories of TERrestiral ENvironmental Observatories (TERENO). The focus of the SOILCan project is to observe the impact of climate change on water and matter budgets in different grass and arable land lysimeters (Bogena et al., 2012). A monitoring network of lysimeter stations was established across a rainfall and temperature transect, and lysimeters were transferred between the stations to subject them to different rainfall and temperature regimes (Pütz et al., 2013). The SOILCan setup and the transfer of lysimeters enable a comparison of water and matter fluxes in the same soil under different climatic conditions. The lateral separation of the lysimeter from its location in the landscape disturbs lateral inflows and outflows such as surface runoff and run-on and lateral flow on sloping subsurface soil horizons. Lysimeters are therefore not suited to investigate soil water balances at locations where these nonlocal controls on the soil water balance are important. The separation of the lysimeter from its surroundings also introduces an artificial boundary at the bottom that may affect the soil water balance of the lysimeter. The classically used bottom boundary of a lysimeter is a seepage-face boundary through which water can only leave when the soil is saturated and through which no upward inflow is possible. Disconnecting the capillary connection with deeper soil affects the drainage and prevents capillary rise. Several studies have shown that upward directed water fluxes from shallow groundwater tables and deeper soil layers serve as an additional water supply for evapotranspiration processes (Schwaerzel and Bohl, 2003; Yang et al., 2007; Luo and Sophocleous, 2010; Karimov et al., 2014). A seepage-face boundary condition may lead to a bias in the drainage (Stenitzer and Fank, 2007) and in the solute transport processes (Abdou and Flury, 2004; Boesten, 2007) so that lysimeter observations are not directly transferable to fieldscale conditions (Vereecken and Dust, 1998; Flury et al., 1999). However, methods have been developed to control the bottom boundary of a lysimeter so that the water balance and moisture profiles in the lysimeter correspond closely with those that would prevail in the undisturbed soil profile (Fank and Unold, 2007). The lysimeters in SOILCan have a controlled bottom boundary condition using a rake of suction candles that enables upward and downward flow of water from and to a weighted leachate tank. To ensure the lysimeter water dynamics are according to the field dynamics, the pressure head at the bottom is controlled and adjusted to measured pressure heads in an undisturbed soil profile next to the location where the lysimeter is installed and at the same depth as the bottom of the lysimeter. An adjustable control algorithm takes into account different soils and conductivities, allowing the bidirectional pumping system to control the water flow direction across the lysimeter bottom to minimize pressure head differences between the field and the lysimeter.

Often, lysimeters are transferred from the place where they were sampled (also for practical reasons) to another location. For transferred lysimeters this approach leads to artifacts since the properties and the hydrogeological setting of the soil profile where the control pressure head is measured may differ from the soil in the lysimeter and the conditions at the site where the lysimeter was taken. Furthermore, changing boundary conditions at the soil surface due to, for instance, climate change will have an effect on the hydrogeological conditions, the water and matter balance in the soil profile, and consequently the pressure head that should be used to control the bottom boundary. Therefore studies of climate change impacts on water fluxes in soils using transferred lysimeters have to take into account that a shift of the climatic conditions will alter the top as well as the bottom boundary of soil monoliths. We hypothesize that the feedback between changing climate conditions, groundwater table depths, and boundary conditions that have to be applied at the bottom of lysimeters have important consequences for the water balance in the lysimeters. Not considering these feedbacks may lead to incorrect conclusions about the effect of climate change on changes of water and matter fluxes in soils.

To assess the potential impact of different bottom boundary conditions on the soil water balance of transferred lysimeters, a numerical study in soils was conducted. The use of synthetic data from numerical studies has the advantage that the assumed truth is known (Schelle et al., 2013) and that the impact of certain changes on the system can be related to a single or several known factors. Using numerical simulation with the software HYDRUS-1D (Šimůnek et al., 2013), we will define (i) the potential impact of different approaches to control the bottom boundary on the water fluxes across the lysimeter, (ii) the sensitivity of water fluxes toward a changing water table depth, and (iii) the feedback between water table change, climate change, and drainage within a fixed hydrogeological setting. On the basis of this study, a proposal for the control of the bottom boundary condition of transferred lysimeters will be made to enable a measurement setup (SOILCan network) that allows quantifying the influence of climate change on soil functions and relevant ecosystem variables.

\section{Materials and Methods}

\section{Site Descriptions}

For the simulation experiment, we considered all transfers of arable land lysimeters from four test sites of the SOILCan climate change lysimeter network. Lysimeters were transferred from Bad 
Lauchstädt (BL), Dedelow (Dd), Sauerbach (Sb), and Selhausen (Se) to the central tests sites for arable land lysimeters in BL and Se (see Table 1). Further information about the lysimeter sites, lysimeter transfer, soil texture, weather station, groundwater table depths, and mean annual climatic conditions during the simulation period (1981-2010) is given in Table 1.

The transfer of arable land lysimeters to the central test site in BL represents a climate change scenario (1981-2010) with a decrease in mean annual precipitation (range: 17 to $215 \mathrm{~mm}$ ) and an increase in mean annual air temperature (range: 0.1 to $0.7^{\circ} \mathrm{C}$; exception, $\mathrm{Se}-0.9^{\circ} \mathrm{C}$ ). The transfer of arable land lysimeters to the central test site Se corresponds to a scenario (1981-2010) with increases in air temperature and precipitation. Changes in mean annual air temperature are up to $1.6^{\circ} \mathrm{C}$ and annual amount of rain up to $215 \mathrm{~mm}$ (1981-2010). The higher annual rainfall amount in Se can be mainly related to wetter conditions during winter and autumn months.

\section{Definition of Simulated Scenarios}

The temporal evolution of the pressure head (values $-/+=$ unsaturated/saturated soil conditions) at 1.4-m soil depth depends on the local climate conditions, soil properties (water retention and hydraulic conductivity), and the depth of groundwater table. Simulations in soil profiles down to a groundwater table are used to obtain and/or mimic time series of pressure heads at 1.4-m depth. These pressure heads are then used to control the bottom boundary of the transferred lysimeters, which represent truncated soil profiles. Figure 1 shows the simulation proceeding for a transfer of soil from $\mathrm{Sb}$ to the central test site in BL. In a first step, we simulated pressure heads and fluxes in the soil profile where the lysimeter was taken (origin) to have the basis for comparison and identify the change in soil water balance components due to the transfer and due to the use of different scenarios to control the bottom boundary of transferred lysimeters. A second simulation represents the current control of transferred lysimeters at the central test sites of the SOILCan network and will be called the Scenario 0 (S0). In this scenario, pressure heads that are observed in the soil profile at

Table 1. Basic information about test sites characteristics.

\begin{tabular}{|c|c|c|c|c|c|c|c|c|c|c|c|c|c|}
\hline \multicolumn{2}{|l|}{ Test site } & \multirow{2}{*}{\multicolumn{2}{|c|}{ Coordinates }} & \multirow{3}{*}{ Weather station $\dagger$} & \multirow[b]{2}{*}{ Altitude } & \multirow{2}{*}{$\begin{array}{l}\text { Groundwater } \\
\text { level } \neq\end{array}$} & \multirow{2}{*}{$\begin{array}{l}\text { Texture } \\
\text { class } §\end{array}$} & \multicolumn{3}{|c|}{ Profile mean } & \multicolumn{3}{|c|}{ Mean annual } \\
\hline \multirow[t]{2}{*}{ Origin } & Transfer & & & & & & & Sand & Silt & Clay & Temp. & Rainfall & $\mathrm{ET}_{\mathrm{P}} \mathrm{g}$ \\
\hline & \multirow[b]{2}{*}{ Se } & \multirow[b]{2}{*}{$51^{\circ} 23^{\prime} 37^{\prime \prime} \mathrm{N}$} & \multirow[b]{2}{*}{$11^{\circ} 52^{\prime} 45^{\prime \prime} \mathrm{E}$} & & \multicolumn{2}{|c|}{$-\mathrm{m} \longrightarrow$} & \multirow[b]{2}{*}{ SiLo } & \multicolumn{3}{|c|}{ 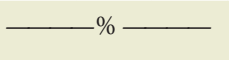 } & \multirow{2}{*}{$\begin{array}{l}{ }^{\circ} \mathrm{C} \\
9.6\end{array}$} & $-\mathrm{mm}-$ & - \\
\hline Bad Lauchstädt (BL) & & & & Halle- Kröllwitz & 113 & 2 & & 12.9 & 66.3 & 20.8 & & 503 & 633 \\
\hline Dedelow (Dd) & $\mathrm{BL}, \mathrm{Se}$ & $53^{\circ} 22^{\prime} 2^{\prime \prime} \mathrm{N}$ & $13^{\circ} 48^{\prime} 11^{\prime \prime} \mathrm{E}$ & Angermünde & 41 & 3 & SaLo & 55.0 & 27.0 & 18.0 & 8.9 & 522 & 659 \\
\hline Sauerbach (Sb) & $\mathrm{BL}, \mathrm{Se}$ & $52^{\circ} 04^{\prime} 47^{\prime \prime} \mathrm{N}$ & $11^{\circ} 16^{\prime} 58^{\prime \prime} \mathrm{E}$ & Magdeburg & 143 & 9 & SiLo & 8.9 & 71.9 & 19.2 & 9.5 & 520 & 646 \\
\hline Selhausen (Se) & $\mathrm{BL}$ & $50^{\circ} 52^{\prime} 9^{\prime \prime} \mathrm{N}$ & $6^{\circ} 27^{\prime} 1^{\prime \prime} \mathrm{E}$ & $\begin{array}{l}\text { Jülich Forsch.- } \\
\text { Anlage }\end{array}$ & 104 & 4 & SiLo & 16.4 & 65.4 & 18.2 & 10.5 & 718 & 643 \\
\hline $\begin{array}{l}\text { † Stations from the G } \\
\neq \text { Assumption of a cor } \\
\S \text { According to USDA } \\
\text { \& Potential evapotran }\end{array}$ & $\begin{array}{l}\text { man We } \\
\text { tant gro } \\
\text { extural }\end{array}$ & $\begin{array}{l}\text { her Service. } \\
\text { dwater table } \\
\text { ssification ch } \\
\text { O Penman- }\end{array}$ & th. & & & & & & & & & & \\
\hline
\end{tabular}

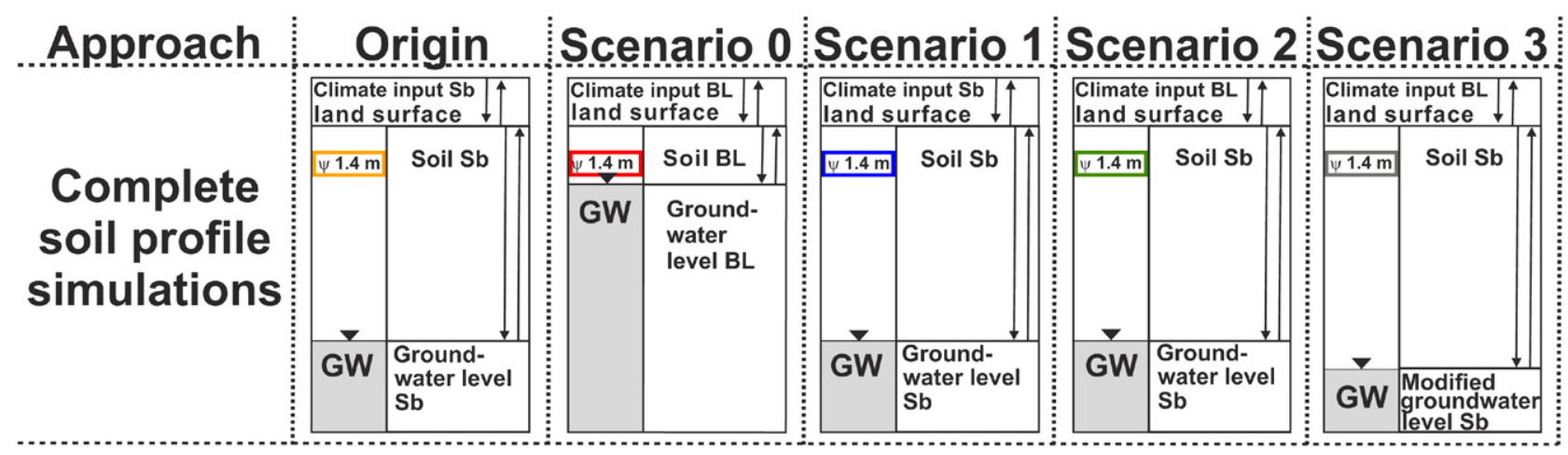

Fig. 1. Experimental setup to derive synthetic data for the control of lysimeter bottom boundary derived by five approaches exemplarily for the lysimeter transfer from Sauerbach $(\mathrm{Sb})$ to the central test site Bad Lauchstädt $(\mathrm{BL})$. The approaches to derive pressure heads in 1.4-m soil depth from a complete soil profile to control the truncated soil of a lysimeter are the following: the origin approach represents conditions to calculate the soil water balance at the site where the lysimeter was taken from. The scenario Scenario 0 (S0) uses the climate conditions, soil characteristics, and groundwater (GW) level from BL (current control approach). The S1 uses the climate input, soil characteristics, and groundwater levels from Sb. The S2 uses climate conditions from BL and the soil characteristics and groundwater levels from Sb. The S3 uses climate from BL and the soil characteristics and 2-m declined groundwater level from $\mathrm{Sb}$. 
the site where the lysimeters are transferred to are used to control the bottom boundary of the transferred lysimeters. These control pressure heads are influenced by the soil properties and groundwater table depths at the site where the lysimeters are transferred to and therefore differ from the soil properties of the lysimeters and the groundwater table depths in the profiles where the lysimeters were taken from. To evaluate the artifacts caused by this control of the lysimeter bottom boundary and to derive an alternative suited approach, water balance simulations were run for three additional scenarios. In Scenario 1 (S1), we used pressure heads at 1.4-m depth that were measured and/or simulated in the soil profile at the site where the lysimeters were taken from to control the lysimeter bottom conditions, that is, the bottom boundary condition in the truncated soil profile simulations was identical to the one in Scenario origin. However, these pressure heads are influenced by the climate at the site where the lysimeters were taken from and may therefore lead to artifacts when used to control the bottom boundary of lysimeters that are transferred to other sites with a different climate. Therefore we defined a Scenario 2 (S2) which used pressure heads that are simulated by using the soil properties and the groundwater table depths from the site where the lysimeters were taken and the climate from the site where the lysimeters were transferred to. Although this approach takes account of the hydraulic properties and hydrological setting of the soil profile at the site from where the lysimeters were taken and the climatic boundary conditions at the site where they are transferred to, feedbacks between the climate and the groundwater table depth are not considered. When groundwater recharge decreases over a long time period, groundwater tables will sink. To consider these feedbacks, lateral water flow in the phreatic aquifer below the vadose zone, which depends on the hydrogeological setting of the region where the lysimeters are taken from, should be considered. Since there is a lot of uncertainty about this setting, we decided to evaluate the potential feedback between climate change and groundwater depth changes with Scenario 3 (S3) by assuming that the static groundwater level from $S 2$ declines by $2 \mathrm{~m}$ when lysimeters are transferred from a wetter to a drier site or increases by $1 \mathrm{~m}$ when they are transferred from a drier to a wetter site. The decline or increase of water table was chosen arbitrarily. Information about the simulation setup of the different scenarios that were used to derive the control pressures at the bottom of the transferred lysimeters is summarized in Table 2.

Several studies have shown the interdependence of land surface fluxes and groundwater dynamics (Kollet and Maxwell, 2008; Maxwell and Kollet, 2008; Ferguson and Maxwell, 2010; Soylu et al., 2011). To explain the differences between the scenarios because of different groundwater table depths and to evaluate the effect of the groundwater table depth on soil water fluxes systematically, additional simulations in which the water table depth varied from 1.4 to $20 \mathrm{~m}$ were performed. In the scenarios used so far, only the effect of a static groundwater table on the water balance of lysimeters was considered. Therefore additional simulations were conducted that consider the interactions between groundwater table depth and drainage-capillary rise within a fixed and hypothetical hydrogeological setting. We defined hydrogeological properties that control lateral groundwater flow such as the depth of an impermeable layer, the hydraulic conductivity of the groundwater layer, and the distance between surface water bodies that drain groundwater.

\section{Model Setup and Parameterization}

To model the impact of different bottom boundaries on the water balance of lysimeters, we used the one-dimensional water flow model HYDRUS-1D (Šimůnek et al., 2013). The program solves numerically the Richards equation for unsaturated water flow. The upper boundary was a time dependent atmospheric boundary condition (daily resolution). Since the objective of this study was to investigate the effect of the bottom boundary control on the soil water balance and not to describe the water balance in the real lysimeters as accurately as possible, we made a few simplifying assumptions. We assumed a homogenous mean soil texture from the top to the bottom of the soil profile. The hydraulic soil parameters for the water retention curve and unsaturated hydraulic conductivity in the Mualem-van Genuchten model (van Genuchten, 1980) were estimated from the averaged sand, silt, and clay content in the soil profile (see Table 3) by using the ROSETTA database. Saturated hydraulic conductivity $\left(\mathrm{K}_{S}\right)$ parameters estimated for the silt texture were replaced by the corresponding values from Carsel and Parrish (1988) to obtain a more realistic unsaturated conductivity for structured silt soils (Schlüter et al., 2013). The bottom boundary of the complete soil profile simulations was defined assuming a constant groundwater table depth at the bottom of the simulated soil profile (see Table 1). For the simulations in the lysimeters, we considered a soil profile of $1.4-\mathrm{m}$ depth. To mimic the real control system of the lysimeter bottom boundary, time dependent pressure heads were defined at the bottom of the lysimeter. Time series of pressure heads at the bottom boundary of the lysimeters were obtained from simulated pressure heads at $1.4-\mathrm{m}$ depth in the complete soil profiles that are considered for the origin and the $\mathrm{S} 0$ to $\mathrm{S} 3$ scenarios. Potential evapotranspiration $\left(\mathrm{ET}_{\mathrm{P}}\right.$ ) was calculated by the FAO-Penman-Monteith equation (FAO, 1990), assuming an albedo of 0.25 (-) for a wheat crop (Piggin and Schwerdtfeger, 1973) and by using daily data of relative humidity, wind speed, sunshine hours, and minimum and maximum air temperature. The meteorological data for a 30-yr time period from 1981 until 2010 were obtained from weather stations of the German Weather Service (DWD): Se (Jülich Forsch.-Anlage), BL (HalleKröllwitz), Sb (Magdeburg), and Dd (Angermünde). Missing values were completed by a linear interpolation between nearby stations of the German Weather Service.

Beer's law was used to split the $\mathrm{ET}_{\mathrm{P}}$ into potential evaporation $\left(E_{\mathrm{P}}\right)$ and transpiration $\left(T_{\mathrm{P}}\right)$ fluxes as follows:

$E_{\mathrm{P}}=\mathrm{ET}_{\mathrm{P}} \exp \left(-\alpha_{i} \mathrm{LAI}\right)$ 
Table 2. Overview of the climate conditions, soil profiles, and groundwater (GW) table depths that were used to simulate the control pressure heads at the bottom of the lysimeters for the different scenarios.

\begin{tabular}{|c|c|c|c|c|c|c|c|c|c|c|c|c|c|c|c|c|}
\hline $\begin{array}{l}\text { Test site and } \\
\text { abbreviation }\end{array}$ & Transfer & \multicolumn{3}{|l|}{ Origin } & \multicolumn{3}{|c|}{ Scenario 0} & \multicolumn{3}{|l|}{ Scenario 1} & \multicolumn{3}{|c|}{ Scenario 2} & \multicolumn{3}{|c|}{ Scenario 3} \\
\hline & & & & $\mathrm{m}$ & & & $\mathrm{m}$ & & & $\mathrm{m}$ & & & $\mathrm{m}$ & & & $\mathrm{m}$ \\
\hline Dedelow, Dd & & $\mathrm{Dd}$ & $\mathrm{Dd}$ & 3 & $\mathrm{Se}$ & $\mathrm{Se}$ & 4 & Dd & $\mathrm{Dd}$ & 3 & $\mathrm{Se}$ & $\mathrm{Dd}$ & 3 & $\mathrm{Se}$ & $\mathrm{Dd}$ & 2 \\
\hline Sauerbach, Sb & & $\mathrm{Sb}$ & $\mathrm{Sb}$ & 9 & $\mathrm{Se}$ & $\mathrm{Se}$ & 4 & $\mathrm{Sb}$ & $\mathrm{Sb}$ & 9 & $\mathrm{Se}$ & $\mathrm{Sb}$ & 9 & $\mathrm{Se}$ & $\mathrm{Sb}$ & 8 \\
\hline Sauerbach, Sb & & $\mathrm{Sb}$ & $\mathrm{Sb}$ & 9 & $\mathrm{BL}$ & $\mathrm{BL}$ & 2 & $\mathrm{Sb}$ & $\mathrm{Sb}$ & 9 & $\mathrm{BL}$ & $\mathrm{Sb}$ & 9 & $\mathrm{BL}$ & $\mathrm{Sb}$ & 11 \\
\hline Selhausen, Se & & $\mathrm{Se}$ & $\mathrm{Se}$ & 4 & $\mathrm{BL}$ & $\mathrm{BL}$ & 2 & $\mathrm{Se}$ & $\mathrm{Se}$ & 4 & $\mathrm{BL}$ & $\mathrm{Se}$ & 4 & $\mathrm{BL}$ & $\mathrm{Se}$ & 6 \\
\hline
\end{tabular}

Table 3. Hydraulic parameters for the Mualem-van Genuchten model (van Genuchten, 1980) of each test site were obtained from the HYDRUS-1D implemented ROSETTA database (Schaap et al., 2001), and saturated hydraulic conductivity for silt loam at Bad Lauchstädt, Sauerbach, and Selhausen where replaced by a value derived by soil texture class from Carsel and Parrish (1988).†

\begin{tabular}{|c|c|c|c|c|c|c|}
\hline \multirow{2}{*}{ Test site } & $\theta_{\mathrm{r}}$ & $\theta_{\mathrm{s}}$ & $\alpha$ & $n$ & $K_{\mathrm{s}}$ & $\tau$ \\
\hline & \multicolumn{2}{|c|}{$\mathrm{cm}^{3} \mathrm{~cm}^{-3}$} & \multicolumn{2}{|l|}{$\mathrm{cm}^{-1}$} & \multicolumn{2}{|l|}{$\mathrm{cm} \mathrm{d}^{-1}$} \\
\hline Bad Lauchstädt & 0.0737 & 0.4461 & 0.0053 & 1.6298 & 10.80 & 0.5 \\
\hline Sauerbach & 0.0737 & 0.4539 & 0.0056 & 1.6305 & 10.80 & 0.5 \\
\hline Selhausen & 0.0685 & 0.4389 & 0.0048 & 1.6576 & 10.80 & 0.5 \\
\hline
\end{tabular}

$+\theta_{\mathrm{r}}$, residual water content; $\theta_{\mathrm{s}}$, saturated water content; $\alpha$ and $n$, empirical shape parameters; $K_{\mathrm{s}}$, saturated hydraulic conductivity; $\tau$, empirical tortuosity factor.

$$
T_{\mathrm{P}}=\mathrm{ET}_{\mathrm{P}}\left[1-\exp \left(-\alpha_{i} \mathrm{LAI}\right)\right]
$$

where $\alpha_{i}$ is $0.463(-)$ (Šimůnek et al., 2013) and LAI $\left(\mathrm{cm}^{2} \mathrm{~cm}^{-2}\right)$ is the leaf area index. The seasonal development of the LAI of wheat was approximated by a linear relation from sowing ( 1 March) until midseason (1 May) when it reached a maximum of $3.6\left(\mathrm{~cm}^{2} \mathrm{~cm}^{-2}\right)$ (Breuer et al., 2003) and after which it remained constant until ripening started (1 June). The evolution of LAI during ripening until harvest ( 1 July) was approximated by a linear decrease from LAI $3.6\left(\mathrm{~cm}^{2} \mathrm{~cm}^{-2}\right.$, 1 June) until LAI $2\left(\mathrm{~cm}^{2} \mathrm{~cm}^{-2}\right.$; July). After harvest, soil stayed bare (LAI $=0 \mathrm{~cm}^{2} \mathrm{~cm}^{-2}$ ) until the next growing season on 1 March. The potential evaporation, $E_{\mathrm{p}}$, was used as flux boundary condition at the soil surface until a critical threshold pressure head, hcrit $=-100,000 \mathrm{~cm}$ at the soil surface, was reached. When this pressure head was reached, the evaporation flux from the soil surface was calculated by the prescribed critical pressure head. The potential transpiration, $T_{\mathrm{p}}$, was linked to the depth-integrated potential water sink term. The potential water sink term is proportional to the normalized root length density which is described by the Hoffman and Van Genuchten (1983) function. The evolution of rooting depth for wheat was simulated by the Verhulst-Pearl logistic growth function (Šimůnek and Suarez, 1993), and the root growth factor was defined so that $50 \%$ of the rooting depth is reached at the first half of the growing season (16 May). The initial root growth time was set on 1 March with an initial rooting depth of $1 \mathrm{~cm}$ and harvest time on $1 \mathrm{July}$, with a maximum rooting depth of $120 \mathrm{~cm}$ for spring wheat (Allen et al., 1998). The potential water uptake is reduced when the soil is nearly saturated and when the soil water potential decreases below a critical value. The relation between actual water uptake and soil water potential was described by the Feddes et al. (1978) stress response function. The used Feddes parameters for the root water uptake were set according to values for wheat from Wesseling et al. (1991). The water uptake by roots is assumed to be zero at pressure heads higher than $0 \mathrm{~cm}$ (anaerobic stress) and lower than $-16,000 \mathrm{~cm}$ (water stress), which corresponds to the permanent wilting point. The optimal range for water uptake is between -1 and $-500 \mathrm{~cm}$ for a potential transpiration rate of $0.5 \mathrm{~cm} \mathrm{~d}^{-1}$ and between -1 and $-900 \mathrm{~cm}$ for a potential transpiration rate of 0.1 $\mathrm{cm} \mathrm{d}^{-1}$. A linear decrease of water uptake is assumed between the limiting pressure heads and wilting point.

For the vegetation parameters, LAI, rooting depth, and their change over time were kept the same for all simulations. Therefore, feedbacks between weather- and climate-dependent vegetation dynamics and the hydrological system, which are important for climate change impact studies (van Walsum and Supit, 2012; Pangle et al., 2014), were not considered. Ecohydrological vegetation feedbacks influence the upper boundary conditions and root water uptake in the soil profile. Since we did not consider these feedbacks, it must be noted that our simulations do not represent how the upper boundary conditions of transferred lysimeters will change. However, the objective of this study is to investigate how 
to control the bottom boundary conditions of transferred lysimeters so that the effect of changing upper boundary conditions due to climate change, including feedbacks with vegetation dynamics, can be monitored in these systems without introducing a systematic bias resulting from improper bottom boundary conditions.

As initial conditions, we assumed a hydrostatic equilibrium from the groundwater table up to $1 \mathrm{~m}$ above the groundwater table. Above this depth, pressure head was assumed to be constant with depth and equal to $-100 \mathrm{~cm}$. For the lysimeter, the same initial pressure heads as in the complete soil profile between the bottom of the lysimeter and the soil surface were taken. A two year spin-up phase was used to minimize the effect of the chosen initial conditions. Long-term mean pressure head, actual evaporation $\left(E_{\mathrm{a}}\right)$, actual transpiration $\left(T_{\mathrm{a}}\right)$, and drainage (negative value) or upward flux (by capillary rise, positive value) that were simulated in the truncated profiles or lysimeters for the different approaches were compared.

To examine the impact of a changing groundwater depth on evapotranspiration and drainage or upward flux, we varied the static groundwater table depth (bottom boundary) from $1.4 \mathrm{~m}$ up to 20 $\mathrm{m}$ for all four soils in Bad Lauchstädt and Selhausen. To account for feedback mechanisms between changing climate, groundwater table depth, and drainage, we conducted a sensitivity analysis in which we varied hydrogeological settings that determine lateral groundwater flow, such as the depth of an impermeable layer on which a groundwater table develops that discharges into drains that are located on this impermeable layer. This was done exemplarily for the Selhausen soil. To account in HYDRUS-1D for a dynamic positioning of the water table during the season and a lateral flow or drain discharge on top of an impermeable layer, we used a system dependent bottom boundary condition derived from the Hooghoudt equation (Šimůnek et al., 2013). The drain discharge (drainage) $q_{\text {drain }}\left(\mathrm{cm} \mathrm{d}^{-1}\right)$ of a homogeneous soil profile in which the drains are located on top of an impermeable layer can be calculated by:

$q_{\mathrm{drain}}=\frac{h_{\mathrm{dr}}}{\gamma_{\mathrm{dr}}}$

where $h_{\mathrm{dr}}$ stands for the height of the water table $(\mathrm{cm})$ above the drain at the midpoint between the drains and $\gamma_{d r}$ for the total drainage resistance $(d)$. The $\gamma_{d r}$ is the sum of the radial flow and the entrance resistance, and can be calculated by Eq. [4]:

$\gamma_{\mathrm{dr}}=\frac{L_{\mathrm{dr}}^{2}}{4 K_{\mathrm{H}} h_{\mathrm{dr}}}+\gamma_{\mathrm{entr}}$

where $L_{\mathrm{dr}}$ is the drain spacing $(\mathrm{cm}), K_{\mathrm{H}}$ is the horizontal saturated hydraulic conductivity $\left(\mathrm{cm} \mathrm{d}^{-1}\right)$ of the groundwater layer above the drain system (which was set to $15 \mathrm{~cm} \mathrm{~d}^{-1}$ ), and $\gamma_{\text {entr }}$ is the entrance resistance into the drains (d). The parameter $\gamma_{\text {entr }}$ was set to zero, as we assumed that the convergence of stream lines to the infinite perforations in the drainage tube does not lead to an additional flow resistance and head loss. The depth of the impermeable layer was varied from $4 \mathrm{~m}$ until $20 \mathrm{~m}$ with a fixed $L_{\mathrm{dr}}$ of $200 \mathrm{~m}$. The relation between the groundwater table depth and drainage in Eq. [3] allows solving the soil water flow equation without having to prescribe pressure head or drainage at the bottom boundary. Therefore, both groundwater table depth and drainage and how they change when the upper boundary conditions change are simulated.

To compare the simulated dynamic groundwater table depths with fixed groundwater table depths, we defined a time-averaged groundwater layer thickness, $h_{\mathrm{dr}, \mathrm{eff}}$, that would lead to the same average drainage, $\left\langle q_{\text {drain }}\right\rangle$ :

$h_{\mathrm{dr}, \mathrm{eff}}=\sqrt{\frac{\left\langle q_{\mathrm{drain}}\right\rangle L_{\mathrm{dr}}^{2}}{4 K_{\mathrm{H}}}}$

The effective average groundwater layer thickness $h_{\mathrm{dr} \text {,eff }}$ can be related to the time-averaged groundwater layer thickness $\left\langle h_{\mathrm{dr}}\right\rangle$ and its temporal variance $\sigma^{2}$ hdr as:

$h_{\mathrm{dr}, \mathrm{eff}}=\sqrt{\left\langle h_{\mathrm{dr}}\right\rangle^{2}+\sigma_{\mathrm{hdr}}^{2}}$

\section{Results and Discussion Impact of Different Bottom Boundary Conditions on the Water Balance of Lysimeters}

The distribution of pressure heads at 1.4-m soil depth during the 30 -yr simulation period that were used in the different approaches to control the bottom boundary of the lysimeters are shown as box plots in Fig. 2. Also shown in Fig. 2 are the pressure head distributions in the soil profiles at the sites where the lysimeters were taken (origin). For S0, the pressure heads are equal to those in the soil profiles at the site where the lysimeters are installed. For S1, they are equal to the distribution of pressure heads at the site where the lysimeters were taken (origin). Average yearly transpiration, evaporation, and drainage or upward flux for the different control approaches are given as stacked bar plots in Fig. 3 .

\section{Transfer to the Central Test Site Selhausen}

The larger precipitation due to the transfer of soils to Se ( 74 to 236 $\mathrm{mm}$ ) led to a larger drainage in all transferred lysimeters for all considered controls of the bottom boundary. For the BL lysimeter, the upward directed water flux by capillary rise at the original location changed to a net drainage. The transpiration was larger in the lysimeters transferred to $\mathrm{Se}$ (max. $17 \mathrm{~mm}$ ), except for the lysimeters from $\mathrm{BL}$ in which the transpiration rate was smaller than at the original location $(6 \mathrm{~mm})$. Also, the evaporation rates 

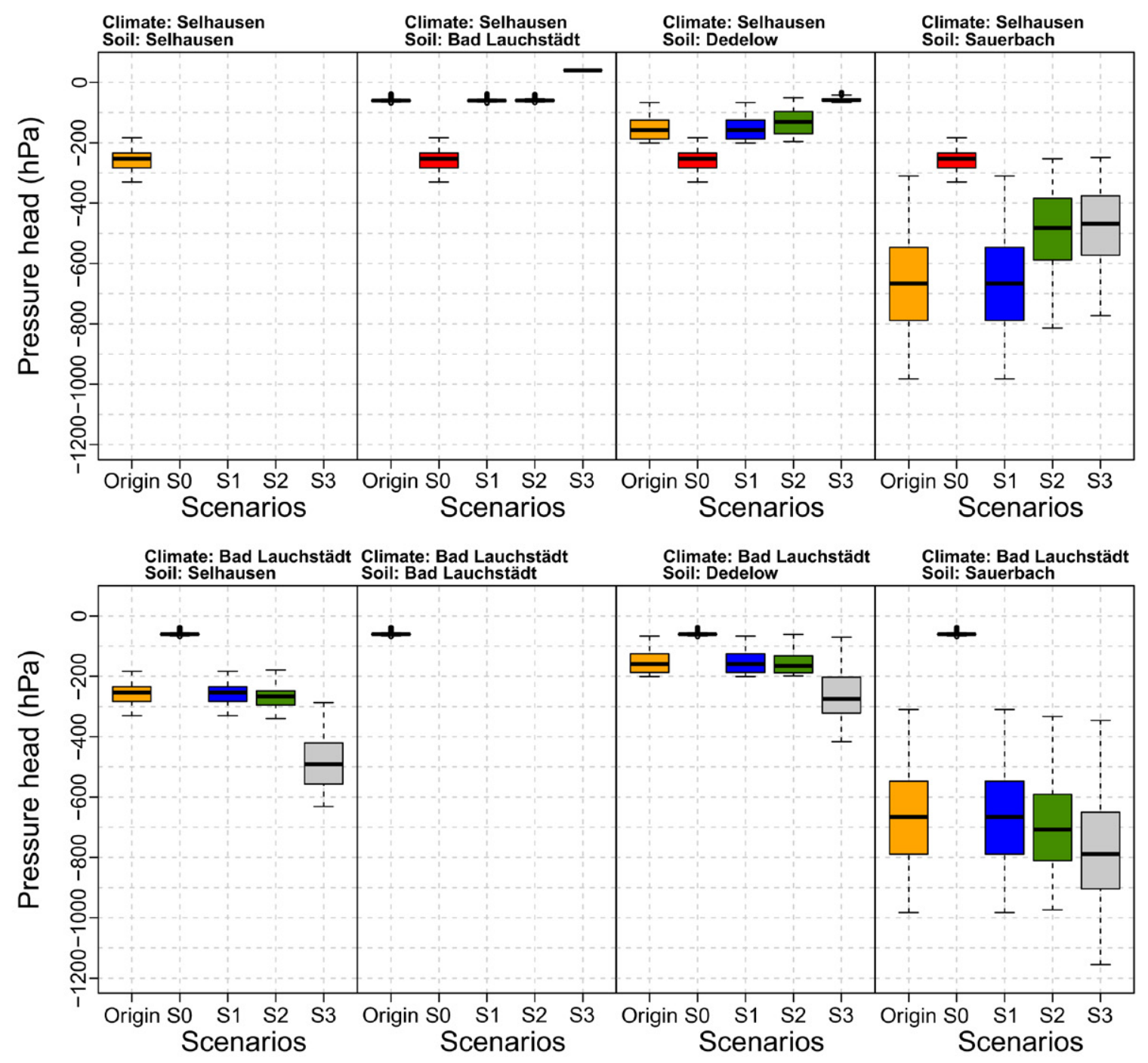

Fig. 2. Pressure heads at 1.4-m depth from complete soil profile simulations at the site where the lysimeter was taken from (origin) and pressure heads that were used to control the bottom boundary of the lysimeters transferred to the central test site Se (top subplots) and BL (bottom subplots) for the different scenarios: $\mathrm{S} 0-\mathrm{S} 3$.

were higher in comparison with the original location (max. 109 $\mathrm{mm}$ ), with exception of the $\mathrm{S} 0$ of the lysimeter from BL in Se, where evaporation rates declines by more than $18 \mathrm{~mm}$. Using a bottom boundary from scenario simulations that was determined by a profile with a deeper groundwater table led to lower pressure heads at the bottom of the lysimeter (Fig. 2) and therefore to a larger drainage (Fig. 3). The influence of capillary rise from the water table on the soil water fluxes across the boundaries of the lysimeter declined with increasing depth to groundwater table (see $\mathrm{Sb}$ to Se in Fig. 3). However, the sensitivity of drainage or upward flux to the depth of the groundwater table depends not only on the depth to the groundwater table, but also on the soil properties. The coarser textured soil from Dd showed a smaller sensitivity of drainage on the depth to groundwater table. The larger pore size in the coarser textured Dd soil led to a smaller capillarity and capillary rise than in the other soils that have a finer texture and smaller pores ( $\mathrm{Li}$ et al., 2013). Comparing the differences between
S1 and S2 represents the effect of the change in climate on the simulated pressure heads at the bottom of the lysimeter in the soil profiles with the same groundwater table depth (see Fig. 2) and the effect of using these simulated pressure heads to control the bottom boundary (see Fig. 3). Since the climate was wetter in Se than in the other locations, the simulated pressure heads at the bottom of the lysimeter were higher for S2 than for S1. But only in the $\mathrm{Sb}$ profile, which has a deep groundwater table, there was a considerable increase in pressure heads. But, when compared with the difference between simulated drainage between $S 0$ and $S 1$, the difference between $S 1$ and S2 was small. For the other profiles, the pressure heads at the bottom of the lysimeter were stronger, as they were controlled more by the presumed groundwater table depth in the soil profile than by the climate conditions at the soil surface. A low impact from climate conditions on the simulated fluxes in the transferred lysimeters might be related to the use of a constant water table (disconnected from land surface fluxes) in 

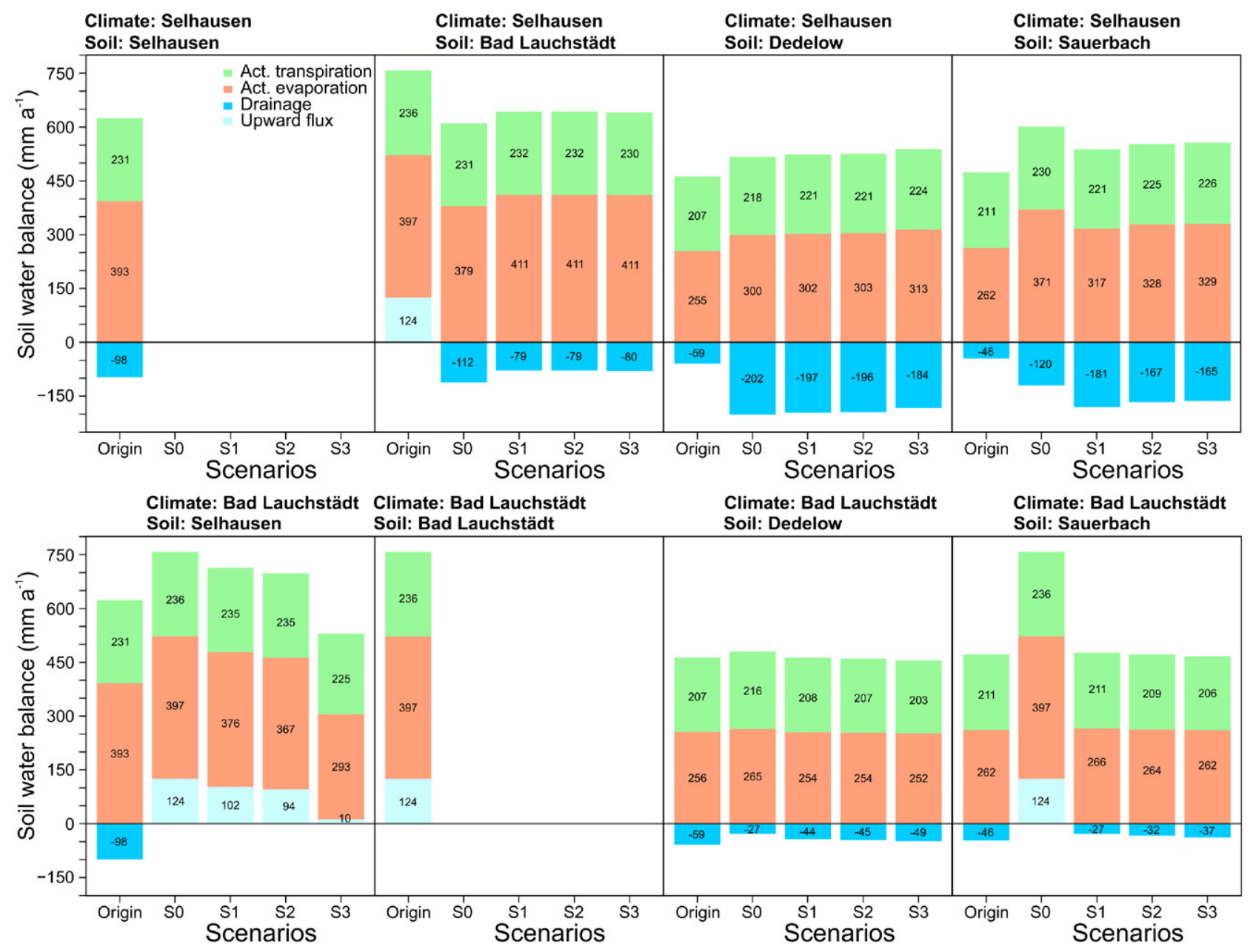

Fig. 3. Averaged yearly transpiration, evaporation, and drainage (negative) or upward flux (positive) from lysimeter profile simulations (1981-2010). The water balance of the lysimeters were simulated at the sites where the lysimeters were taken from (origin) and at the sites where the lysimeters were transferred to. We used four different scenarios ( $\mathrm{S} 0$ to $\mathrm{S} 3$ ) to control the bottom boundary of transferred lysimeters at the central test sites. Information about climate conditions and soil origin is given in the subplot headings.

the complete soil profile simulations. Seasonal weather, drainage (Taylor et al., 2013) and vegetation conditions lead to fluctuations of the water table, which play an important role for the diurnal or seasonal cycle of water uptake by plants (Gribovszki et al., 2010). The raised groundwater level by $1 \mathrm{~m}$ from $\mathrm{S} 2$ to $\mathrm{S} 3$ led to higher simulated pressure heads at the bottom of the lysimeter. This led the $\mathrm{Dd}$ and $\mathrm{Sb}$ soils to a decrease in simulated drainage (max. 12 $\mathrm{mm}$ ). For the BL soil, the simulated transpiration and evaporation from S1 and S2 were equal to the potential evapotranspiration. A further increase in groundwater level would therefore not further enhance the evapotranspiration. Conversely, a too shallow water table can lead to anaerobic conditions in the effective root zone and negatively affect the plant transpiration (Soylu et al., 2014). The order of magnitude of simulated fluxes at the lysimeter bottom boundary is, in consideration of the assumptions in the simulation setup (homogenous mean soil texture and constant water table), in good agreement with observations for two exemplary test sites. Measured drainage for the station Se was $-53 \mathrm{~mm} \mathrm{a}^{-1}$ (average value of three lysimeters, $2014-2015)$ and for Dd was $-23 \mathrm{~mm}$ $\mathrm{a}^{-1}$ (average of six lysimeters, 2012-2013).

\section{Transfer to the Central Test Site Bad Lauchstädt}

The central test site $\mathrm{BL}(502 \mathrm{~mm})$ is drier than the $\mathrm{Se}(718 \mathrm{~mm})$, $\operatorname{Dd}(522 \mathrm{~mm})$, and $\mathrm{Sb}(520 \mathrm{~mm})$ test sites. The rainfall, but also the potential evapotranspiration, is higher at the latter two sites $(\mathrm{Dd}=$ $659 \mathrm{~mm} ; \mathrm{Sb}=646 \mathrm{~mm})$ than at $\mathrm{BL}(633 \mathrm{~mm})$. The groundwater table in $\mathrm{BL}(2 \mathrm{~m})$ is shallower than at the other sites. In general, the simulated drainage of the transferred lysimeters to BL was smaller than at the original locations. For the soils with a finer texture (silt loam: $\mathrm{BL}, \mathrm{Se}$, and $\mathrm{Sb}$ ), the shallow groundwater table in $\mathrm{BL}$ and the simulated pressure heads that were used in $S 0$ led to an upward flux of water into the lysimeter and higher evapotranspiration. Upward directed water flux from a shallow water table increased the water storage in the effective root zone and enhanced the evapotranspiration (Leterme et al., 2012). This upward water flux compensated for the difference between the potential evaporation rate and 
precipitation in $\mathrm{BL}$ so that the simulated evapotranspiration in these lysimeters was equal to the potential evapotranspiration. In the sandy loam soil from Dd the simulated pressure heads at 1.4-m depth for $\mathrm{S} 0$ were not large enough to sustain a sufficient capillary rise to the root zone or soil surface so that for this soil, transpiration and evaporation were lower than the potential rates, and there was still drainage. When soil profiles with groundwater table depths of the original locations (S1 and S2) or even lower (S3) were considered to control the bottom boundary of the lysimeter, the effect of capillary rise and groundwater uptake was smaller, drainage increased, and evapotranspiration was reduced. For the Se profile, a decrease of the groundwater table by $2 \mathrm{~m}$ led to a significant decrease in upward fluxes (difference between the S2 and S3). This was neither observed for the Sb profile, which had a similar texture as the Se profile but a deep groundwater table, nor for the Dd profile, which had a coarser texture but a similar groundwater table.

In general, average annual water fluxes were strongly influenced by the surrounding field conditions (depth to water table and soil properties). The use of a shallow water table and finer textured soil in the scenario was essential for the water availability in the soil, influenced the plant water use (Soylu et al., 2014), and enhanced the evaporation from bare soil (Jin et al., 2014).

\section{Impact of Boundary Conditions on Dynamics of Water Fluxes at the Bottom of Lysimeters}

Figure 4 gives an overview of the average monthly drainage or upward flux and their annual variability (period 1981 to 2010) across the lysimeter bottom for the different bottom boundary controls. Drainage occurred mainly during the autumn and winter months and was relatively small during spring. However, in summer the flux was directed upward. The intra-annual variation of the average monthly drainage or upward flux declined for bottom boundary control scenarios with deeper groundwater tables. In general, we found that using a bottom boundary control based on a scenario with a higher water table led to a higher upward flux during summer and higher drainage during winter. This indicates that a control by S0 will lead to an overestimation of upward flux during summer and of drainage during winter when the water table at the site where the lysimeters are transferred to is higher than at the original site (e.g., lysimeters transferred to BL). The opposite is true for lysimeters that are transferred to a site with a lower groundwater table (e.g., BL lysimeter transferred to Se). The climatic boundary conditions at the top of the lysimeter influence the time course of the fluxes at the bottom of the lysimeter (see difference between the origin and the other scenarios). But, for the differences in climate conditions between the original sites and the sites where the lysimeters were transferred to, the effect of the different climate conditions on the pressure heads that are used to control the bottom boundary was not large (see Fig. 2 and the difference between S1 and S2). Consequently, S1 and S2 hardly led to differences in simulated monthly averaged water fluxes at 1.4-m depth.

The results indicate additionally that at sites with a relatively shallow groundwater table and silty soils, upward water fluxes during summer can be considerable. Tension-controlled lysimeters are required to reproduce these fluxes so that the soil water balance in the field can be mimicked in the lysimeter system. But an inappropriate control of the pressure head based on pressure heads that are obtained for a nonrelevant water table depth (e.g., from a site that is not related to the site where the lysimeters were taken from) can lead to large deviations of these fluxes.

With the water that flows back into the lysimeter system, dissolved chemical substances are also transported. A correct mimicking of the water fluxes at the bottom of the lysimeter is therefore also of importance for a correct representation of the chemical balance, for example, nitrogen balance (Klammler and Fank, 2014) or tracer experiments in the lysimeter. Seasonal changes in saturated conditions at the lysimeter bottom can impact chemical processes, for example, the denitrification rate (Anderson et al., 2014) or the estimation of solute transport parameters (Rühle et al., 2015). Within the SOILCan lysimeter setup, we assume that chemical reactions and temperature in the leachate tank, where the leachate is stored, are comparable with that in the surrounding soil at the corresponding depth of $1.4 \mathrm{~m}$. However, when biogeochemical gradients are present in the soil profile, the chemical composition of the water that flows back into the soil profile will differ from that that leaches from the profile. How the water composition of the water that flows back into the system needs to be controlled so that the chemical balance of the lysimeter system corresponds with that of the field profile requires further investigation. In case of a negative water balance over the year, additional water has to be added with a similar chemical composition of the seasonal outflow (e.g., prepared in laboratory) for a correct chemical balance. The importance of bottom boundary conditions in zero tension lysimeter systems to represent pesticide balances in field soil profiles has been demonstrated by Boesten (2007). But similar studies for tension-controlled lysimeters are still missing.

\section{Impact of the Different Controls of the Bottom Boundary on the Water Contents in the Lysimeters}

In Fig. 5, time-averaged water contents and the standard deviations of the temporal fluctuation at a certain depth are shown for the different approaches. Again, the depth of the water table in the soil profiles that were considered to define the control of the lysimeter bottom boundary played an important role for the vertical water content profile (Chen and $\mathrm{Hu}, 2004$ ). The S0 (groundwater table at the location where the lysimeters were transferred to) led to considerably different water content profiles than those of other approaches (based on groundwater tables at locations where the lysimeters were taken). Besides affecting the mean water content, 


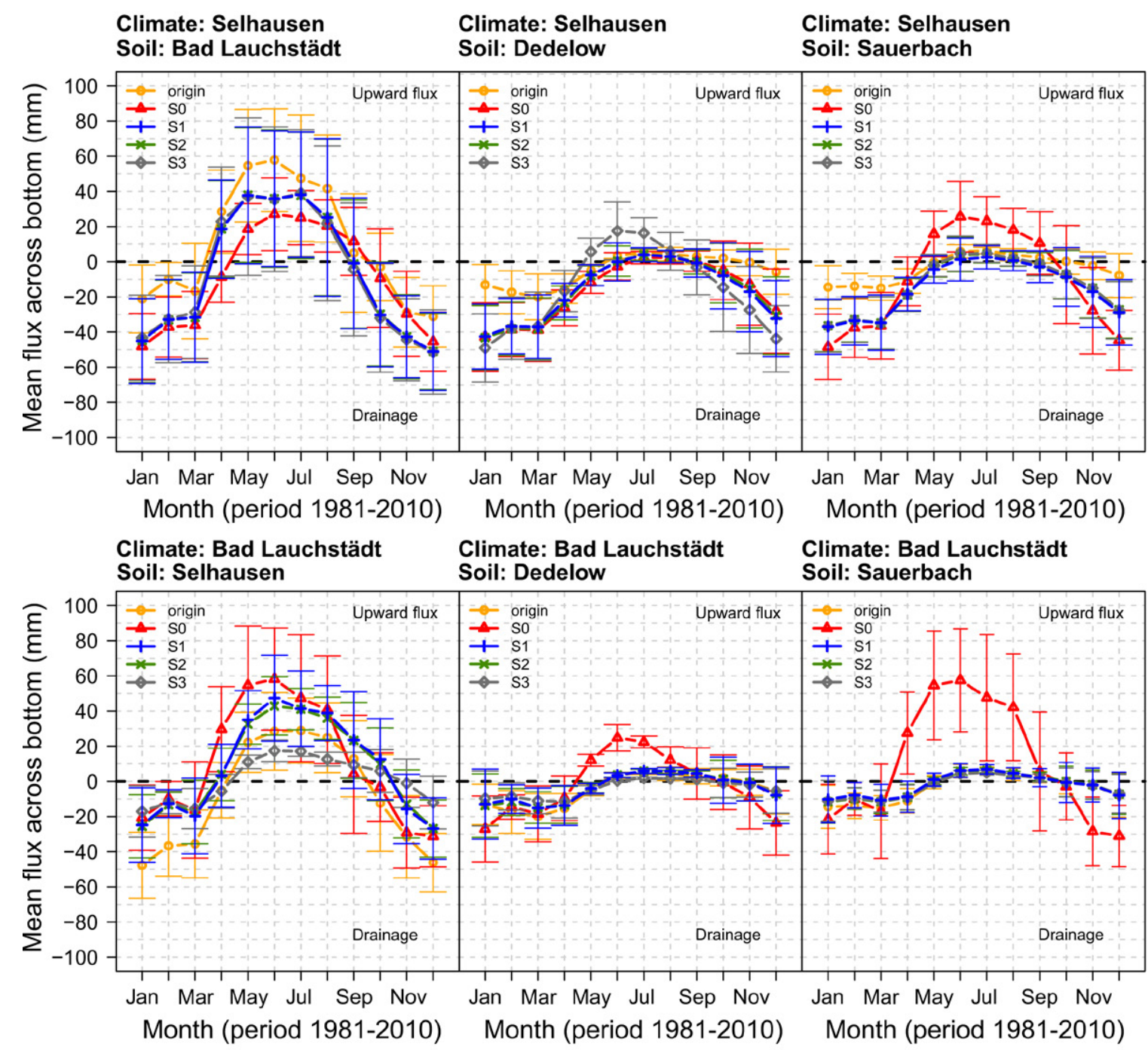

Fig. 4. Monthly averaged water flux across the bottom boundary of lysimeters that remained at their original locations (origin) and lysimeters that were transferred from BL, Dd, Sb, and Se to the central test sites BL and Se and in which the pressure heads at the bottom boundary are prescribed by S0, S1, S2, and S3. Positive values represent upward water fluxes (capillary rise), and negative values represent downward water fluxes (drainage). Error bars represent the standard deviation of the monthly averaged fluxes in different years.

the groundwater table depth also influenced the temporal variability of the soil water content with smaller variability when the water table depth was high (e.g., S0 for lysimeters transferred to $\mathrm{BL}$ ) and higher variability when the groundwater table was lower (e.g., S3 for Se lysimeters transferred to BL). The effect of the climate on the soil moisture in the soil columns can be evaluated by comparing the moisture contents at the original locations with those using $S 2$ to control the lysimeters bottom boundary, as both control pressure heads are simulated in a soil profile with the same water table depth and soil properties as at the original site, but using climate of the location where the lysimeters were transferred to. The Dd and Sb lysimeters that were transported to Se (wetter climate) showed higher water contents in the top of the soil profiles than at the original location. For the BL lysimeter transferred to $\mathrm{Se}$, the water content profile seems to be completely dominated by the shallow water table depth in BL so that there was hardly an influence of the climate on the water content profile in this soil. The Se lysimeter that was transferred to BL (drier climate) showed lower water contents at the top of the soil profile than at the original location. The Dd and Sb lysimeters that were transferred to BL did not show a difference in soil water content profile with the profile at the original location since the climate at those locations was similar to that in BL.

A comparison between the water content profiles in the lysimeter from S1 and S2 shows the impact of using pressure heads at the bottom of the lysimeter that were observed at the site where the lysimeter were taken $(\mathrm{S} 1)$ and the test site where the lysimeter were transferred to (S2). Only for the Sb lysimeter that was transferred to Se was a noticeable effect present. But the effect vanishes closer to the soil surface where the water content profiles of S1 and S2 were closer to each other than the profiles from S1 and S0. 


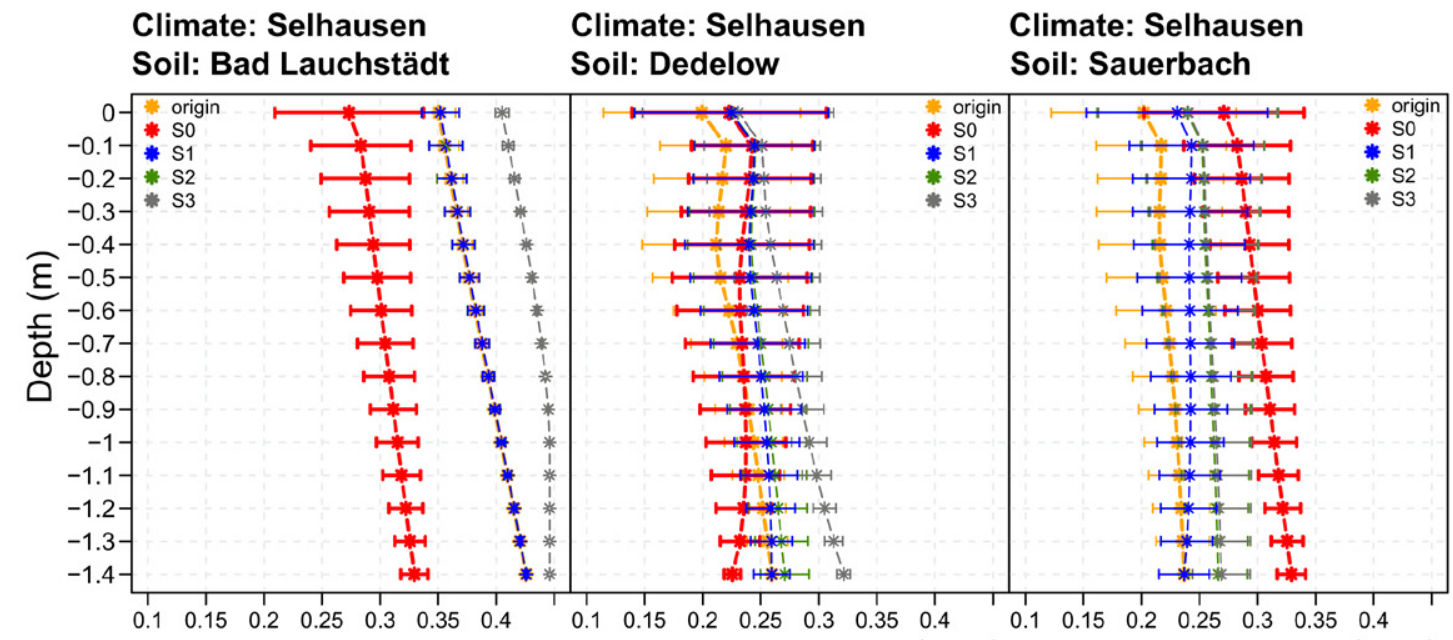

Soil water content $\left(\mathrm{cm}^{3} \mathrm{~cm}^{-3}\right)$ Soil water content $\left(\mathrm{cm}^{3} \mathrm{~cm}^{-3}\right)$ Soil water content $\left(\mathrm{cm}^{3} \mathrm{~cm}^{-3}\right)$

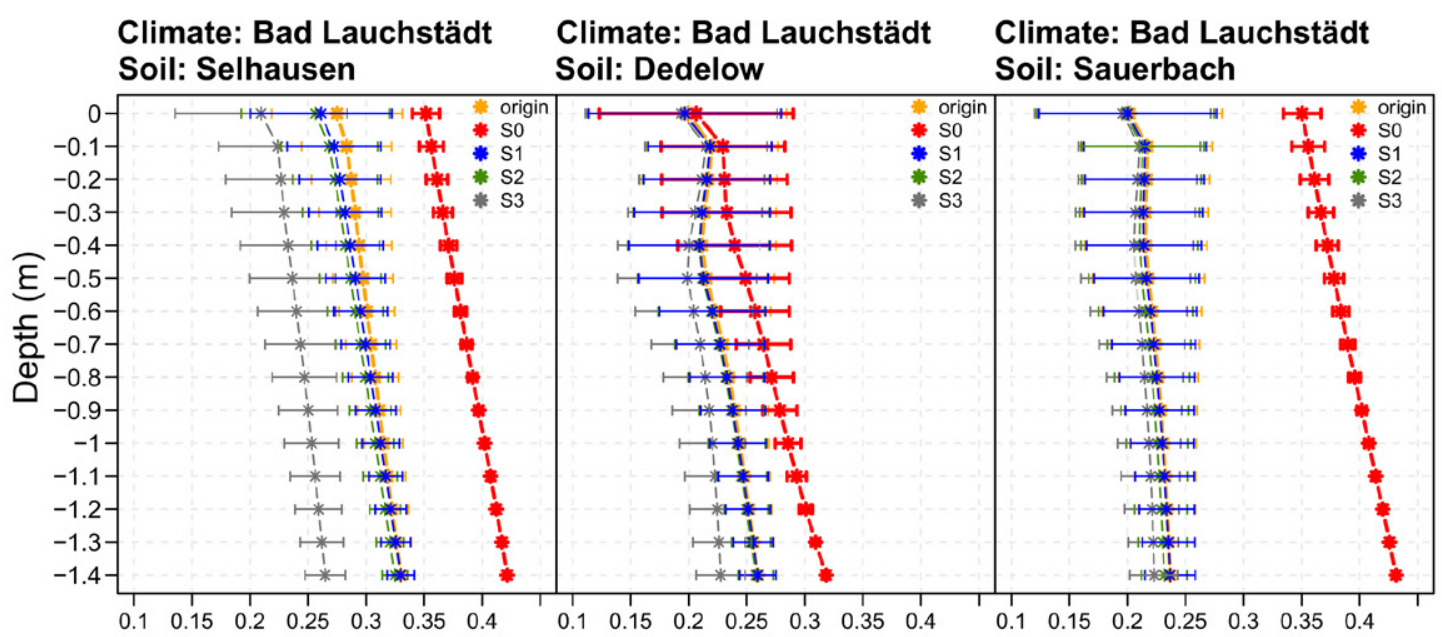

Soil water content $\left(\mathrm{cm}^{3} \mathrm{~cm}^{-3}\right)$ Soil water content $\left(\mathrm{cm}^{3} \mathrm{~cm}^{-3}\right)$ Soil water content $\left(\mathrm{cm}^{3} \mathrm{~cm}^{-3}\right)$

Fig. 5. Time-averaged water contents in lysimeters that remained at their original locations (origin) and in lysimeters that were transferred from BL, $\mathrm{Dd}, \mathrm{Sb}$, and Se to the central test sites BL and Se and in which the pressure heads at the bottom boundary are prescribed by S0, S1, S2, or S3. Error bars represent the standard deviation of the temporal variations of the soil water content. The water contents of the soil from BL at Se (climate) are identical for $S 1$ and S2.

Finally, when comparing S3 (groundwater table changes compared with the depth at the original location) and S2, lowering of the water table in the Se and Dd profiles led to lower water contents in the lysimeters that were transferred to the drier BL site. For the Sb lysimeter, the effect of further lowering the groundwater table on the water content profiles was small since the water table at the original location was already quite deep and did not influence the water dynamics in the soil profile a lot. For the lysimeters that were translocated to Se, an increase in water table height led to wetter soil profiles except for the $\mathrm{Sb}$ profile, where the groundwater table was deep.

When we compare the different approaches, it seems that the groundwater table depth in the soil profile was more important for the control of the bottom boundary conditions of the lysimeter than the climate. This implies that using pressure heads that are measured in the soil profile at the site where the lysimeters are transferred to for controlling the bottom boundary of the lysimeters may lead to considerable artifacts in the lysimeters water balance. The main focus of the translocation concept in SOILCan is to observe changes in water and matter fluxes in the same soil under different climate conditions. The artifacts from the current bottom boundary control (SO) will lead to a nonclimate changerelated alteration of the water balance in the considered transferred terrestrial ecosystem. A better option seems to use pressure heads that are measured at the sites where the lysimeters originate from. This bottom boundary control setup for transferred lysimeters allows a direct comparison of changes in soil processes and soil functions under different climate regimes with identical bottom boundary conditions. 
The important role of the groundwater table on the soil water balance is further discussed in the following sections, where the sensitivity of drainage or upward flux to the groundwater table depth and feedbacks between drainage and groundwater table are evaluated.

\section{Sensitivity of Water Fluxes Toward a Changing Water Table Depth}

Figure 6 illustrates the actual evapotranspiration $\left(E_{\mathrm{a}}\right)$ and drainage-upward flux as a function of depth to groundwater table for all soils under the climatic conditions of both central test sites (Se and BL). The drainage generally increases, whereas the evapotranspiration decreases with increasing groundwater table depth. The $\mathrm{ET}_{\mathrm{a}}$ and drainage or upward flux simulations were sensitive to groundwater table depth changes. The sensitivity vanishes for a deep groundwater table when $\mathrm{ET}_{\mathrm{a}}$ becomes water limited and in the silt loam soils (all except Dd) and also for shallow groundwater tables when $\mathrm{ET}_{\mathrm{a}}$ becomes energy limited. It should be noted that we did not consider groundwater table depths above $1 \mathrm{~m}$. In these cases, simulated $\mathrm{ET}_{\mathrm{a}}$ decreased with decreasing water table depth because too wet soil conditions also induce a transpiration reduction. Kollet and Maxwell (2008) named the region with strong correlations between water table depth and land surface energy fluxes as the "critical zone." The lower boundary of the critical zone represents the point where the water table is disconnected from the land surface (Maxwell and Kollet, 2008). In their study, this zone was defined for the Little Washita watershed in central Oklahoma (soil: loam-loamy sand) and ranged between 1 and $5 \mathrm{~m}$. Following the concept of a critical zone from Kollet and Maxwell (2008), we defined the upper and lower limits of the sensitive ground water table (GWT) region (critical zone) as the depth where $\left|\mathrm{dET}_{\mathrm{a}} / \mathrm{dGWT}\right|>5 \mathrm{~mm} \mathrm{~m}^{-1} \mathrm{yr}^{-1}$. The threshold value for $\left|\mathrm{dET}_{\mathrm{a}} / \mathrm{dGWT}\right|$ was chosen arbitrarily but represents the region where drainage-upward flux was sensitive to the groundwater table depth and enables an estimation of a soilspecific critical zone.

The thickness of the critical zone from Fig. 6 (colored bars at the subplot bottom) showed a strong dependence on soil texture as well as on climatic conditions. Soils with a finer texture showed a significantly thicker and deeper located critical zone than coarser

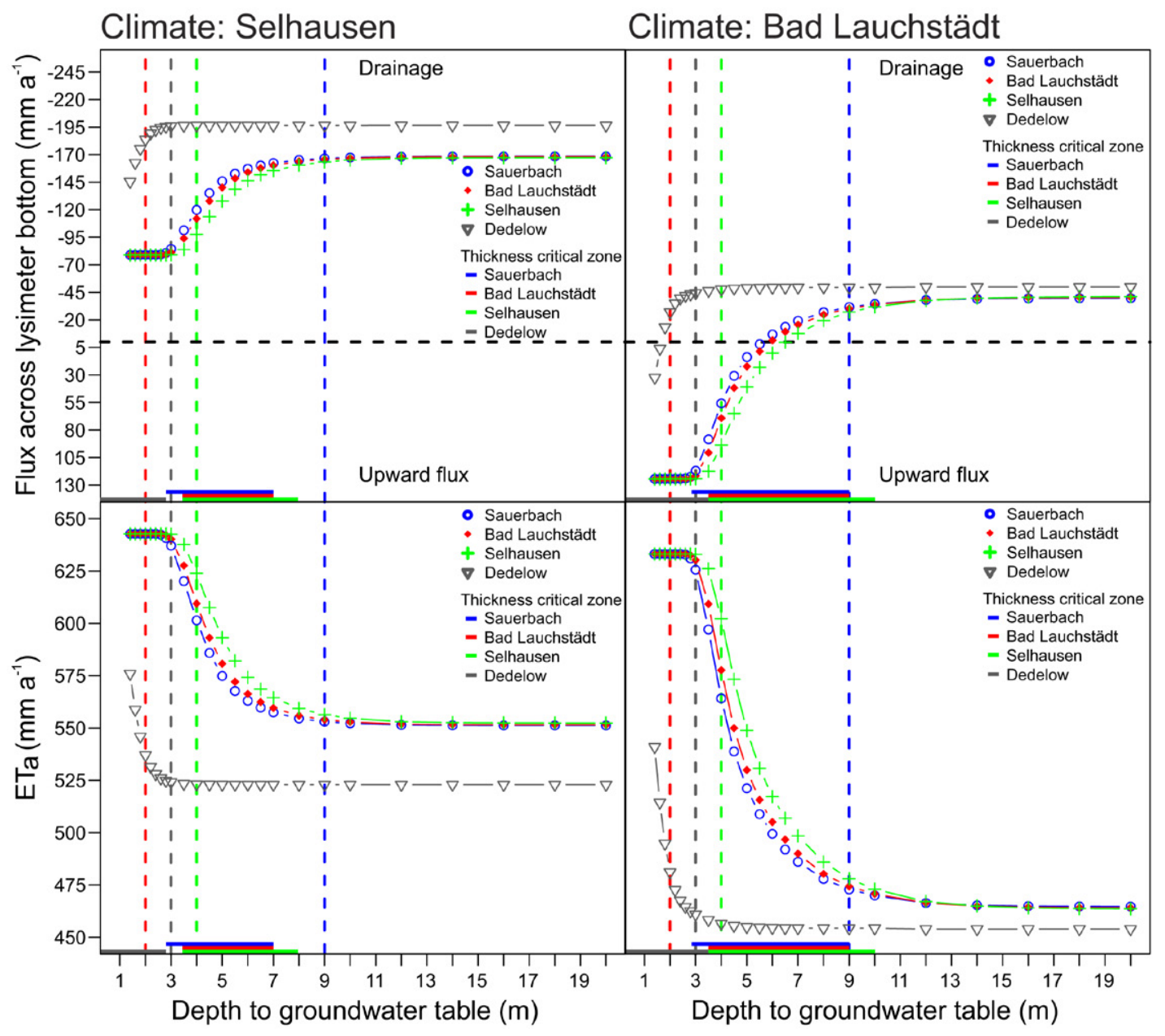

Fig. 6. Yearly water flux across the lower (drainage-upward flux) and upper boundary (evapotranspiration) of a soil profile, which represents the corresponding soil texture class from BL, Dd, Sb, and Se, averaged over $30 \mathrm{yr}$ under the respective climatic conditions at the central test sites Se and BL. Horizontal colored bars at the bottom of each subplot represent the thickness of the soil texture specific critical zone. Vertical colored lines represent the water table depth at the sites where the lysimeters were taken from. 
textured soils. The simulation was in a good agreement with studies by Soylu et al. (2011), who showed that soil properties (texture) affect the depth and the thickness of critical zone. A change in climate regime from wetter to drier conditions, with a smaller precipitation-to-ET $\mathrm{T}_{\mathrm{P}}$ ratio, resulted for the soils with the silt and the sandy loam texture in a thicker critical zone. Finer textured soils showed a much larger increased thickness of the critical zone by a change in climate regime than the coarser textured soil. Additionally, we can see from Fig. 6 the effect of changing the water table at one site to the water table at the corresponding central test site. All soils, where a change of the two water tables was within the soil-specific critical zone (horizontal colored bars at the bottom), showed a considerable change in the drainage or upward flux and evapotranspiration in the soil profile.

When the water table change was not in the critical zone (soil Dd in Se) there was no effect of the groundwater table depth on the change or drainage-upward flux due to a change of the net precipitation. This explains the low sensitivity of water balance components toward a water table change in the scenarios of a coarser soil (Dd) in Fig. 3. The larger change of drainage-upward flux and evapotranspiration due to changing groundwater tables in BL indicates a higher sensitivity of water table changes on the water fluxes in the soil profiles under drier climatic conditions. But the question that needs to be answered is how the groundwater levels will change when the net precipitation changes.

\section{Feedback between Groundwater Change, Climate Change, and Drainage}

In our scenario $S 3$, we used a fixed and preset drop of the groundwater table of $2 \mathrm{~m}$ to evaluate the potential effect of the climate change (wet to drier conditions) on groundwater table depths and its feedback on drainage. This drop was arbitrarily chosen but could, as we demonstrate in this section, be estimated if the hydrogeological settings of the site are considered.

The averaged water table depth, drainage, and water table drop as a function of the drain depth are shown for two different climate conditions: BL and Se (Fig. 7). The water table depth was under wetter conditions (Se) generally higher and showed until $14 \mathrm{~m}$ larger seasonal fluctuations than under drier conditions (BL). Under the BL climate, drainage emerged for drain depths (or impermeable layer depths) deeper than $6 \mathrm{~m}$. It should be noted that this threshold depth corresponds with the groundwater table depth in Fig. 7 where the drainage becomes zero. Drier climate conditions prevented the buildup of a water table and the generation of drainage for drain depths or impermeable layer boundaries shallower than $6 \mathrm{~m}$. Under these conditions, water that perched on the impermeable layer could be completely consumed by evapotranspiration without saturating the soil and generating drainage. Additionally, we have to remark that with simulations under wetter conditions (Se) runoff occurred when drain depth distance between the impervious layer and the soil surface was smaller than $8 \mathrm{~m}$.

The calculated drop of the water table, when the climate shifts from wet to drier conditions, was maximal (around $2.9 \mathrm{~m}$ ) for the threshold drain depth of $8 \mathrm{~m}$ when a groundwater table emerged under the BL conditions. For deeper drain depths, the groundwater table drop decreased to about $2 \mathrm{~m}$ for a drain depth of $20 \mathrm{~m}$. The simulation results for a defined fixed hydrogeological setting indicate that a change in climate conditions will affect the average position and the seasonal behavior of water table depth. A change in water table depth and the seasonal variability goes along with a modified pressure head in the soil at $1.4 \mathrm{~m}$, which impacts the water flux across the boundaries of transferred lysimeters. As an example from simulations with drain spacing of $200 \mathrm{~m}$, considering a groundwater table of $7 \mathrm{~m}$ under wet climate conditions and assuming that it remains constant when the conditions change to drier conditions, the simulated drainage under dry conditions (S2, Fig. 7 red dashed line) would be $9 \mathrm{~mm} \mathrm{yr}^{-1}$. When a drop in the groundwater table due to changing climate conditions from 7 to $9 \mathrm{~m}$ is considered (S3, Fig. 7 red dashed line), the drainage under dry conditions would be $34 \mathrm{~mm} \mathrm{yr}^{-1}$. Also, the effect of the change of the groundwater table depth when the climate changes from drier to wetter conditions could be evaluated from Fig. 7. If the groundwater table is at $7 \mathrm{~m}$ under dry conditions and assumed to be the same under wet conditions (S2, Fig. 7 black dashed line), the drainage under wet conditions would be $151 \mathrm{~mm} \mathrm{yr}^{-1}$. When the groundwater table rise due to the wetter conditions on $6 \mathrm{~m}$ is

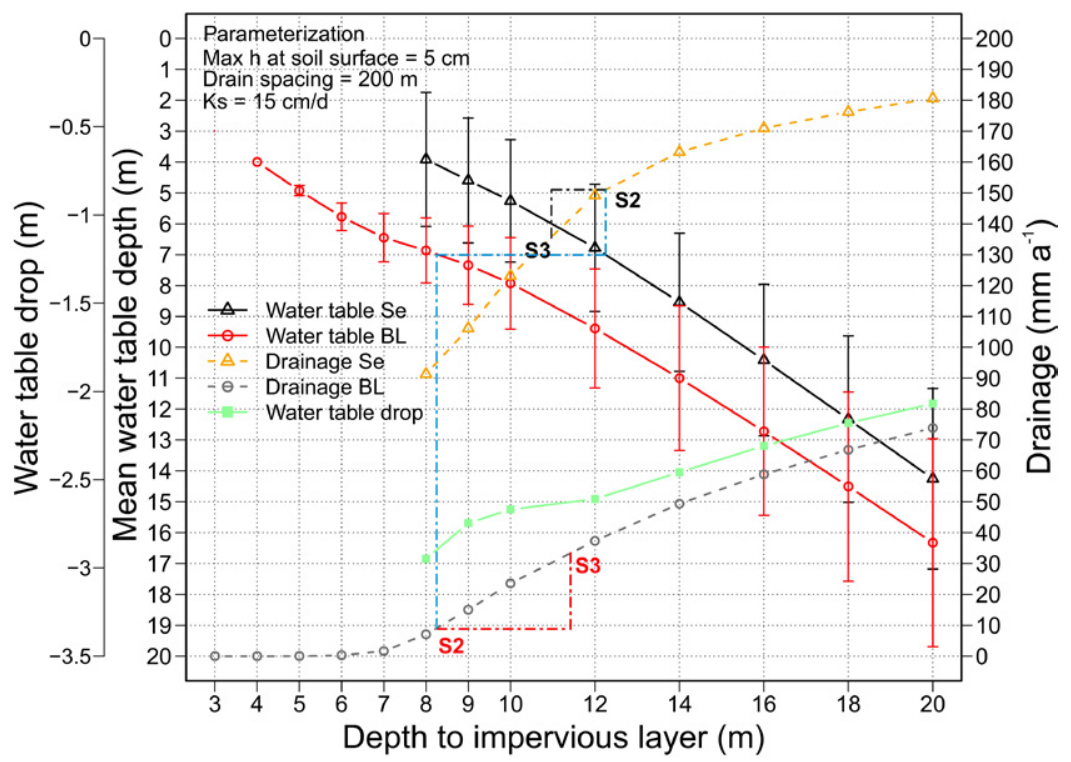

Fig. 7. Sensitivity of mean water table depth, standard deviation, and mean drainage (lateral flow) on top of an impervious layer for the soil from Se with a fixed hydrogeological setting under different climate conditions (Se, triangles; BL, circles). The green line represents the water table drop by a shift from a wetter to a drier and hotter climate. 
considered (S3, Fig. 7 black dashed line), the drainage under wet conditions would be $136 \mathrm{~mm} \mathrm{yr}^{-1}$. The relevance of these changes on the boundary conditions will alter the water flux and cause significant changes on the measured water balance components in the transferred lysimeter.

\section{Conclusions and Outlook}

We used tension-controlled lysimeter systems to study the effect of climate change on soil hydrology. Lysimeters with a similar soil texture were transferred to other locations to simulate the soil water balance under different climatic regimes. With the transfer of lysimeters and/or soils in the simulation setup, not only the atmospheric but also the surrounding subsurface conditions changed and influenced the measured pressure heads that are used to control the bottom boundary of transferred lysimeters. We found that the use of nonappropriate pressure heads, which do not correspond with water table depths and soil textural properties from the site where the lysimeters originated from, can lead to large biases in soil water fluxes and seasonal water flux dynamics across the lysimeter bottom and lead to nonclimate change-related alteration of water availability and fluxes in the considered terrestrial ecosystem. Feedback mechanisms between changing climate conditions (principle weather parameters and net precipitation), groundwater dynamics, and bottom boundary conditions, which are used to control the bottom boundary of transferred lysimeters, can lead to an additional amplification or diminishing of climate change effects on the terms of the water balance in lysimeters. We found that the effect of a changing water table in the field under a different climate regime was rather small in comparison with the difference between the current control approach (S0), which is based on water table depths at the sites where lysimeters are transferred to and which may differ considerably from the conditions at the sites where the lysimeters originate from, and the approach which used measured pressure heads at the site where the lysimeter was taken from (S1). However, the effects from water table change on the water flux in lysimeters were noticeable when the water table was located within a specific critical water table depth range. This region, where land surface and subsurface processes are coupled, was called the critical zone. A sensitivity analysis investigating the impact of different water table depths on the water flux in lysimeters showed a strong dependence of the thickness and depth of the critical zone on soil textural properties and climatic conditions.

The simulation results confirm that not only are aboveground conditions relevant for lysimeter measurements but, moreover, surrounding subsurface conditions are highly important for lysimeters with a tension-controlled bottom boundary. We found that local field conditions led to considerable artifacts on the water balance of transferred and tension-controlled lysimeters when they do not match the conditions of the sites where the lysimeters were extracted from. These findings are also relevant for future lysimeter installations with a tension-controlled bottom boundary system. Changes in soil textural properties and water table depth between the location of excavation and installation can lead to a strong bias in water fluxes across the lysimeter boundaries.

Theoretically, the control of the bottom boundary that includes the effect of changing climate conditions on the pressure heads that are used to control the bottom of the lysimeter (S2 or S3) would be better for studying the effect of climate change on flow and transport processes in transferred soils. However, these bottom boundary conditions can only be derived by simulations which imply uncertainties. In contrast, the bottom boundary control from S1 can be based on actual measurements and shows to be a reliable representative of the bottom boundary control from S2 and S3, unless the change in climate and water table depth are substantial. Therefore, we suggest, for studies with a transfer of soil, managing the bottom boundary by pressure heads that are measured at the place where the lysimeter was taken from (S1). This control setup allows a direct comparison of changes in soil processes and soil functions between soils under rainfall and temperature regimes with identical bottom boundaries conditions.

\section{Acknowledgments}

We acknowledge the support of the TERENO and SOILCan, which was funded by the Helmholtz Association and the Federal Ministry of Education and Research. We thank the German Weather Service for providing meteorological data. In addition, we thank our editor Christine Stumpp for her constructive and helpful comments as well as the anonymous reviewers for their insightful comments and suggestions.

\section{References}

Abdou, H.M., and M. Flury. 2004. Simulation of water flow and solute transport in free-drainage lysimeters and field soils with heterogeneous structures. Eur. J. Soil Sci. 55:229-241. doi:10.1046/j.13652389.2004.00592.x

Allen, R.G., L.S. Pereira, D. Raes, and M. Smith. 1998. Crop evapotranspiration-Guidelines for computing crop water requirements. FAO, Rome.

Anderson, T.R., C.L. Goodale, P.M. Groffman, and M.T. Walter. 2014. Assessing denitrification from seasonally saturated soils in an agricultural landscape: A farm-scale mass-balance approach. Agric. Ecosyst. Environ. 189:60-69. doi:10.1016/j.agee.2014.03.026

Boesten, J.J.T.I. 2007. Simulation of pesticide leaching in the field and in zero-tension lysimeters. Vadose Zone J. 6:793-804. doi:10.2136/ vzj2007.0067

Bogena, H., R. Kunkel, T. Pütz, H. Vereecken, E. Krüger, S. Zacharias, P. Dietrich, U. Wollschläger, H. Kunstmann, H. Papen, H.P. Schmid, J.C. Munch, E. Priesack, M. Schwank, O. Bens, A. Braver, E. Borg, and I. Hajnsek. 2012. TERENO-Ein langfristiges Beobachtungsnetzwerk für die terrestrische Umweltforschung. (In German, with English abstract.) Hydrol. Wasserwirt. 53:138-143.

Brever, L., K. Eckhardt, and H.-G. Frede. 2003. Plant parameter values for models in temperate climates. Ecol. Modell. 169:237-293. doi:10.1016/ S0304-3800(03)00274-6

Briones, M.J.I., P. Ineson, and J. Poskitt. 1998. Climate change and Cognettia sphagnetorum: Effects on carbon dynamics in organic soils. Funct. Ecol. 12:528-535. doi:10.1046/j.1365-2435.1998.00218.x

Carsel, R.F., and R.S. Parrish. 1988. Developing joint probability distributions of soil water retention characteristics. Water Resour. Res. 24:755769. doi:10.1029/WR024i005p00755

Chen, X., and Q. Hu. 2004. Groundwater influences on soil moisture and surface evaporation. J. Hydrol. 297:285-300. doi:10.1016/j.jhydrol.2004.04.019

Fank, J., and G. Unold. 2007. High-precision weighable field Lysimeter-A tool to measure water and solute balance parameters. Int. Water Irrig. 27:28-32. 
FAO. 1990. Food and Agriculture Organization of the United Nations Expert consultation on revision of FAO methodologies for crop water requirements, ANNEX V. FAO. Rome.

Feddes, R.A., P.J. Kowalik, and H. Zaradny. 1978. Simulation of field water use and crop yield, John Wiley \& Sons, New York.

Ferguson, I.M., and R.M. Maxwell. 2010. Role of groundwater in watershed response and land surface feedbacks under climate change. Water Resour. Res. 46:W00F02. doi:10.1029/2009WR008616

Flury, M., M.V. Yates, and W.A. Jury. 1999. Numerical analysis of the effect of the lower boundary condition on solute transport in lysimeters. Soil Sci. Soc. Am. J. 63:1493-1499. doi:10.2136/sssaj1999.6361493x

Gribovszki, Z., J. Szilágyi, and P. Kalicz. 2010. Diurnal fluctuations in shallow groundwater levels and streamflow rates and their interpretation-A review. J. Hydrol. 385:371-383. doi:10.1016/j.jhydrol.2010.02.001

Herndl, M., E.M. Pötsch, A. Bohner, and M. Kandolf. 2011. Lysimeter als Bestandteil eines technischen Versuchskonzeptes zur Simulation der Erderwärmung im Grünland. (In German, with English abstract.) Gumpensteiner Lysimetertagung 14:119-126.

Hoffman, G.J., and M.T. Van Genuchten. 1983. Soil properties and efficient water use: Water management for salinity control. In: Taylor H.M., W.R. Jordan, and T.R. Sinclair, editors, Limitations to efficient water use in crop production. ASA, CSSA, SSSA, Madison, WI. p. 73-85.

Ineson, P., K. Taylor, A.F. Harrison, J. Poskitt, D.G. Benham, E. Tipping, and C. Woof. 1998. Effects of climate change on nitrogen dynamics in upland soils. 1. A transplant approach. Glob. Change Biol. 4:143-152. doi:10.1046/j.1365-2486.1998.00118.x

Jin, X.M., Y.K. Zhang, Y. Tang, G.C. Hu, and R.H. Guo. 2014. Quantifying bare soil evaporation and its relationship with groundwater depth. Int. J. Remote Sens. 35:7567-7582. doi:10.1080/01431161.2014.975374

Karimov, A.K., J. Šimůnek, M.A. Hanjra, M. Avliyakulov, and I. Forkutsa 2014. Effects of the shallow water table on water use of winter wheat and ecosystem health: Implications for unlocking the potential of groundwater in the Fergana Valley (Central Asia). Agric. Water Manage. 131:57-69. doi:10.1016/j.agwat.2013.09.010

Kasteel, R., T. Pütz, and H. Vereecken. 2007. An experimental and numerical study on flow and transport in a field soil using zero-tension lysimeters and suction plates. Eur. J. Soil Sci. 58:632-645. doi:10.1111/j.13652389.2006.00850.x

Klammler, G., and J. Fank. 2014. Determining water and nitrogen balances for beneficial management practices using lysimeters at Wagna test site (Austria). Sci. Total Environ. 499:448-462. doi:10.1016/j.scitotenv.2014.06.009

Kollet, S.J., and R.M. Maxwell. 2008. Capturing the influence of groundwater dynamics on land surface processes using an integrated, distributed watershed model. Water Resour. Res. 44:W02402. doi:10.1029/2007WR006004

Leterme, B., D. Mallants, and D. Jacques. 2012. Sensitivity of groundwater recharge using climatic analogues and HYDRUS-1D. Hydrol. Earth Syst. Sci. 16:2485-2497. doi:10.5194/hess-16-2485-2012

Li, X., S.X. Chang, and K.F. Salifu. 2013. Soil texture and layering effects on water and salt dynamics in the presence of a water table: A review. Environ. Rev. 22:41-50. doi:10.1139/er-2013-0035

Luo, Y., and M. Sophocleous. 2010. Seasonal groundwater contribution to crop-water use assessed with lysimeter observations and model simu lations. J. Hydrol. 389:325-335. doi:10.1016/j.jhydrol.2010.06.011

Maxwell, R.M., and S.J. Kollet. 2008. Interdependence of groundwater dynamics and land-energy feedbacks under climate change. Nat Geosci. 1:665-669. doi:10.1038/ngeo315

Pangle, L.A., J.W. Gregg, and J.J. McDonnell. 2014. Rainfall seasonality and an ecohydrological feedback offset the potential impact of climate warming on evapotranspiration and groundwater recharge. Water Resour. Res. 50:1308-1321. doi:10.1002/2012WR013253

Piggin, I., and P. Schwerdtfeger. 1973. Variations in the albedo of wheat and barley crops. Arch. Meteorol. Geophys. Bioklimatol. Ser. B. 21:365391. doi:10.1007/BF02253314

Pütz, T., K. Kiese, U. Wollschläger, E. Priesack, E. Borg, H. Gerke, H. Papen and $H$. Vereecken. 2013. TERENO-SOILCan: Ein Lysimeternetzwerk zur Untersuchung des Klimawandels. (In German, with English abstract.) In: 15 Gumpensteiner Lysimetertagung, 16-17 Apr. 2013. Höhere Bundeslehr- und Forschungsanstalt für Landwirtschaft (HBLFA) Raumberg-Gumpenstein. p. 57-62.

Rühle, F.A., N. Zentner, and C. Stumpp. 2015. Changes in water table level influence solute transport in uniform porous media. Hydrol. Pro cesses 29:875-888. doi:10.1002/hyp.10200
Scanlon, B.R., D.G. Levitt, R.C. Reedy, K.E. Keese, and M.J. Sully. 2005. Ecological controls on water-cycle response to climate variability in deserts. Proc. Natl. Acad. Sci. USA 102:6033-6038. doi:10.1073/ pnas.0408571102

Schaap, M.G., F.J. Leij, and M.T. van Genuchten. 2001. Rosetta: A computer program for estimating soil hydraulic parameters with hierarchical pedotransfer functions. J. Hydrol. 251:163-176. doi:10.1016/S00221694(01)00466-8

Schelle, H., W. Durner, S. Schlüter, H.-J. Vogel, and J. Vanderborght. 2013. Virtual soils: Moisture measurements and their interpretation by inverse modeling. Vadose Zone J. 12. doi:10.2136/vzj2012.0168

Schlüter, S., H.-J. Vogel, O. Ippisch, and J. Vanderborght. 2013. Combined impact of soil heterogeneity and vegetation type on the annual water balance at the field scale. Vadose Zone J. 12. doi:10.2136/ vzj2013.03.0053

Schwaerzel, K., and H.P. Bohl. 2003. An easily installable groundwater lysimeter to determine waterbalance components and hydraulic properties of peat soils. Hydrol. Earth Syst. Sci. 7:23-32. doi:10.5194/ hess-7-23-2003

Šimůnek, J., and D.L. Suarez. 1993. Modeling of carbon dioxide transport and production in soil: 1. Model development. Water Resour. Res. 29:487-497. doi:10.1029/92WR02225

Šimůnek, J., M. Šejna, H. Saito, M. Sakai and M.T. van Genuchten. 2013. The Hydrus-1D Software Package for Simulating the Movement of Water, Heat, and Multiple Solutes in Variably Saturated Media. Version 4.16, HYDRUS Software Series 3: 340.

Soylu, M.E., E. Istanbulluoglu, J.D. Lenters, and T. Wang. 2011. Quantifying the impact of groundwater depth on evapotranspiration in a semiarid grassland region. Hydrol. Earth Syst. Sci. 15:787-806. doi:10.5194/ hess-15-787-2011

Soylu, M.E., C.J. Kucharik, and S.P. Loheide II. 2014. Influence of groundwater on plant water use and productivity: Development of an integrated ecosystem-Variably saturated soil water flow model. Agric. For. Meteorol. 189-190:198-210. doi:10.1016/j.agrformet.2014.01.019

Stenitzer, E., and J. Fank. 2007 "Tension-free" lysimeters versus "controlled tension" lysimeters-A simulation study. In: Proceedings of the Conference on Diffuse Inputs into Groundwater-Monitoring, Modelling, 29-31 Jan. 2007. Graz, Austria. p.149-152.

Tataw, J.T., R. Hall, E. Ziss, T. Schwarz, C. von Hohberg und Buchwald, H. Formayer, J. Hösch, A. Baumgarten, H. Berthold, K. Michel, and J.G. Zaller. 2014. Soil types will alter the response of arable agroecosystems to future rainfall patterns. Ann. Appl. Biol. 164:35-45. doi:10.1111/ aab. 12072

Taylor, R.G., M.C. Todd, L. Kongola, L. Maurice, E. Nahozya, H. Sanga, and A.M. MacDonald. 2013. Evidence of the dependence of groundwater resources on extreme rainfall in East Africa. Nat. Clim. Change 3:374-378. doi:10.1038/nclimate1731

Thornton, P.K., P.J. Ericksen, M. Herrero, and A.J. Challinor. 2014. Climate variability and vulnerability to climate change: A review. Glob. Change Biol. 20:3313-3328. doi:10.1111/gcb.12581

van Genuchten, M.T. 1980. A closed-form equation for predicting the hydraulic conductivity of unsaturated soils. Soil Sci. Soc. Am. J. 44:892898. doi:10.2136/sssaj1980.03615995004400050002x

van Walsum, P.E.V., and I. Supit. 2012. Influence of ecohydrologic feedbacks from simulated crop growth on integrated regional hydrologic simulations under climate scenarios. Hydrol. Earth Syst. Sci. 16:15771593. doi:10.5194/hess-16-1577-2012

Vereecken, H., and M. Dust. 1998. Modeling water flow and pesticide transport at lysimeter and field scale. In: R. Führ et al., editors, The lysimeter concept. American Chemical Society, Washington, DC. p. 189-202. doi:10.1021/bk-1998-0699.ch014

Wesseling, J.G., J.A. Elbers, P. Kabat, and B.J. van den Broek. 1991. SWATRE: Instructions for input, internal note. Winand Staring Centre, Wageningen, The Netherlands.

Yang, J., S. Wan, W. Deng, and G. Zhang. 2007. Water fluxes at a fluctuating water table and groundwater contributions to wheat water use in the lower Yellow River flood plain, China. Hydrol. Processes 21:717-724. doi:10.1002/hyp.6246

Zacharias, S., H. Bogena, L. Samaniego, M. Mauder, R. Fuß, T. Pütz, M. Frenzela, M. Schwanke, C. Baesslera, K. Butterbach-Bahlc, O. Bense, E. Borgf, A. Bravere, P. Dietricha, I. Hajnsekg, G. Hellef, R. Kiesec, H. Kunstmannc, S. Klotza, J.C. Munchd, H. Papenc, E. Priesackd, H.P. Schmidc, R. Steinbrecherc, U. Rosenbaumb, G. Teutscha, and H. Vereecken. 2011. A network of terrestrial environmental observatories in Germany. Vadose Zone J. 10:955-973. doi:10.2136/vzj2010.0139 